\title{
Coordination Scheme for Restructuring Business Operation of the Single Period Newsvendor Problem
}

\author{
Chiuh-Cheng Chyu and I-Ping Huang \\ Department of Industrial Engineering and Management, Yuan-Ze University, 135 Yuan-Tung Road, Chung-Li 320, Taiwan \\ Correspondence should be addressed to Chiuh-Cheng Chyu; iehshsu@saturn.yzu.edu.tw
}

Received 3 July 2013; Revised 13 September 2013; Accepted 27 September 2013

Academic Editor: Yi-Chung Hu

Copyright ( 2013 C.-C. Chyu and I.-P. Huang. This is an open access article distributed under the Creative Commons Attribution License, which permits unrestricted use, distribution, and reproduction in any medium, provided the original work is properly cited.

\begin{abstract}
This paper presents a coordination scheme for a single period newsvendor problem when both supplier and retailer of the supply chain agree to change the business operation from a market decision power sharing system (Model 1) to a unique decision maker system (Model 2). The supplier is assumed to be a risk-averse decision maker and he will undertake the product quality risk in both models. Model 1 is game theoretic, where the supplier controls the wholesale price, but the retailer controls the order quantity and market price. The bargaining process ends when the supplier has found a wholesale price that maximizes the value of his sales revenue minus the product quality cost. Model 2 is a centralized system where the supplier possesses all decision powers of the market. In general, Model 2 will generate higher total revenue than Model 1 . The aim of this research is to propose a satisfying compromise based on consignment policy to resolve the revenue-sharing conflict in Model 2 due to the additional revenue. An example is provided to illustrate the two models and the proposed coordination scheme, along with managerial insights on the models' benefits. The impacts of several parameters on the scheme are also presented and discussed.
\end{abstract}

\section{Introduction}

In many market channels, both suppliers and retailers share market control power. Each party in a channel wants to use its power to earn more profit. In general, there are two types of supply chain structures: centralized and decentralized [1]. In a centralized structure, the supply chain operates on the basis of centrally made decisions. In a decentralized structure, each retailer makes its own decisions almost independent of the rest of the supply chain. Usually, centralized structures make more total supply chain revenue than decentralized structures. For a decentralized supply chain, if the decisions result in supply chain channel revenue that is equal to the total revenue achieved in a centralized supply chain, the decentralized supply chain is called perfect coordination or channel coordination [2-4].

As market competition intensifies, firms are turning their focus on developing business collaboration strategies into supply chain integration. Integration refers to the agreement of parties within the supply chain on how they will cooperate with each other. Coordination mechanisms, such as markdown money policy [5-8], return (buyback) contracts [9-11], sales rebate contracts $[12,13]$, quantity discounts $[14,15]$, revenue-sharing contracts $[16,17]$, two-part tariff contracts $[17,18]$, consignment contracts $[4,19]$, and quantity flexibility contracts [20], can provide feasible solutions to mitigate or resolve the revenue-conflict for the supply chain members.

The markdown money policy (MMP) is a supplier tactic for promoting retailer ordering quantity. This policy lowers the wholesale price for products not sold by the end of the season and has an advantage of decreasing overstocking risk for the retailer. In returns policy, the retailer can return the unsold units to the supplier with a refund at the end of the season. Thus, returns policy reduces the retailer's cost of excess inventory and encourages the retailer to order more products. It should be noted that the MMP does not require physical return of leftover products, but the returns policy does.

Sales rebate contracts are generally viewed as a powerful policy for promoting retailer sales performance. Linear and target sales rebates are two common types of sales rebate 
contracts. In the linear policy, the supplier pays the retailer a fixed rebate amount for each unit sold, regardless of the quantity sold. The target sales rebate refers to the amount of money paid for each unit sold, beyond a prespecified target sales level [12]. Chiu et al. [13] studied sales rebate contracts in fashion supply chains. Their analyses indicate that a properly designed sales rebate contract can improve expected profits and lower risk levels for both the supplier and the retailer.

Two quantity discount policies commonly used in practice are all-units and incremental-units. In the all-units policy, the order quantity is divided into $m$ intervals $\left\{q_{1}\right.$, $\left.q_{2}, \ldots, q_{m}\right\}$ with $q_{1}<q_{2}<\cdots<q_{m}$. The corresponding purchase cost per unit for order quantity within the interval $\left[q_{i}, q_{i+1}\right)$ is $p_{i+1}$, where $p_{1}>p_{2}>\cdots>p_{m}$. Under the incremental-units policy, when order quantity $q$ is within $\left[q_{i}, q_{i+1}\right)$, the purchase cost per unit is $p_{1}$ for $q_{1}$ units, $p_{2}$ for an additional $q_{2}-q_{1}$ units, ... and $p_{i+1}$ for $q_{i+1}-q$ units.

Revenue-sharing contracts generally coordinate a supply chain as follows: the retailer pays the supplier the total purchase cost for the quantity ordered, plus a fraction of the retailer revenue. On the other hand, two-part tariff contracts specify a fixed amount that the retailer must pay to the supplier, in addition to total purchase cost of order quantity. Consignment is a popular form of business arrangement, where the supplier retains ownership of his inventory, while receiving payment from the retailer based on actual units sold. Ru and Wang [19] studied consignment contracting for the newsvendor problem. Newsvendor problems have been extensively studied in the past decades [21-23]. Qin et al. [24] provided a thorough research review on the contributions for this problem to date, including analyses of customer demand, market price, marketing effort, supplier costs, and retailer risk attitudes.

The single period newsvendor problem is one of the classical problems in inventory management [25]. This simple problem, with its intrinsically appealing optimal solution, has become an extensive research topic since 1950. The importance of analyzing these models is reinforced by the growing time-based competition; as time-based competition increases, product life-cycles decrease so that more products will acquire the attributes of fashion or seasonal commodities. Gallego and Moon [26] mentioned that these newsvendor models can reflect many real life situations and is often used to aid decision making in industries such as fashion and sporting goods, both at the manufacturing and retail levels.

Supply chain coordination is important to achieve a satisfying compromise for both parties in a win-win situation. Many coordination schemes have been proposed for various types of supply chains. Pan et al. [27] provided a detailed review on the revenue-sharing coordination scheme in a supply chain. Wang [28] studied a consignment arrangement with revenue sharing, where the supplier decides the market price and order quantity and retains ownership of leftover goods; for each unit sold, the retailer deducts a percentage from the market price and pays the balance to the supplier. Cachon and Lariviere [16] discovered that revenue sharing is equivalent to buy-backs in a newsvendor case and equivalent to price discounts in a price-setting newsvendor case. They also found that revenue sharing coordinates a supply chain with retailers competing for sales volumes. veen der Veen and Venugopal [29] illustrated that revenue-sharing contracts can optimize and deliver a win-win situation for all the players in a video retail supply chain.

There are many other studies confirming the advantages of revenue sharing in supply chain coordination. Koulamas [30] proposed a revenue sharing policy, which was designed to completely eliminate double marginalization for a standard newsvendor problem. The necessary demand-distributiondependent condition to achieve this objective is derived as follows. Given a production $c$, a market price $p$, and a wholesale price $r_{T}$, find a purchase cost $r^{*}$ plus a revenue share $r_{T}-r^{*}$ per unit sold for the supplier, so that the total supply chain revenue keeps its maximum amount. However, the scheme favors the retailer for any $r_{T}$ within a reasonable range in the standard newsvendor problem. Li et al. [31] presented a coordination scheme for a decentralized system using consignment contract with revenue sharing, where the supplier determines market price and supply quantity and the retailer sets revenue shares. Both members are risk-neutral (expected-value decision makers). The model assumes that the retailer is the leader and the supplier is the follower in a noncooperative game. Their study utilizes Nash bargaining model to develop a coordination scheme of the supply chain, so that both members can increase their profits by cooperating. Linh and Hong [32] studied channel coordination through revenue sharing contracts between a retailer and a supplier in a two-period newsboy problem. Two buying-opportunity models were presented, one for products with long delivery lead time and the other for products with short delivery lead times. The study discussed how the revenue share ratio and wholesale prices are to be determined, in order to achieve channel coordination and a win-win outcome.

$\mathrm{Xu}$ et al. [17] investigated channel coordination in a twoechelon fashion supply chain with risk-averse retailer and price-dependent demand, based on the classic mean-variance (MV) approach in finance. Their study found that revenue sharing contracts and two-part tariff contracts in the supply chain with risk neutral retailers are useful in coordinating the supply chain, while considering the degree of fashion retailers' risk aversion. Shen et al. [8] explored how the MMP performs in fashion supply chains with a risk-averse supplier and a risk-neutral retailer. The supply chain's goal follows MV objective or system-wide expected profit maximization. The study investigated both optimal decisions of the risk-averse supplier, with respect to the MMP contract parameters and the optimal ordering decision of the risk-neutral retailer, so that the whole supply chain can be coordinated.

In this research, two newsvendor supply chain systems considering market risk and quality risk are presented and analyzed. The market risk includes overage cost and shortage cost. The quality risk is the penalty due to selling defective products to customers. The supplier will be responsible for product quality and compensate for defective products sold to customers. In the first system (hereafter referred to as Model 1), the supplier will offer a wholesale price to the retailer, and the retailer will respond with a market price and order quantity based on the wholesale price. 
The supplier will then select the best wholesale price that maximized his total revenue minus the quality cost. In Model 1 , the supplier does not undertake any market risk. The second (Model 2) is a centralized system where the supplier determines market price and supply quantity but still bears the product quality risk. In Model 2, the retailer will play the role of selling products and earns a fraction of market price for each unit sold or called charge rate. In other words, the retailer forgoes his decision power on market price and order quantity in order to induce the supplier to share the market risk. Our research objective is to develop a revenuesharing scheme for changing Model 1 operational pattern to Model 2, given that both parties have common knowledge of the product's price-sensitive market demand. The certainty equivalent (CE) of utility theory is applied to determine the charge rate. $\mathrm{CE}$ is the amount of money equivalent in a decision maker's mind for a given situation involving uncertainty [33].

To the best of our knowledge, few studies on the newsvendor problems have taken into account the product quality risk, which is highly related to random yields of products. Khouja [34] suggested that random yields are an extension of the newsvendor problem. Product quality is an important factor in making a product successful. In practice, not all products sold to customers will function properly. Some are discovered to be defective immediately, whereas others after a period of usage, as often is the case in fashion and sporting goods. Customers usually request replacement for a defective item. The compensation cost will include production cost, additional inspection cost, transportation cost, and other processing costs. In our study, Bayesian analysis is applied to reduce the product quality risk, since this method can utilize sampling information and compute quality loss in terms of monetary or utility value in order to minimize overall product quality loss.

In our study, we focus on the design of consignment contracts using CE to coordinate both parties of a supplieroriented newsvendor supply chain. The supplier wishes to provide incentive to the retailer via the contract in order to benefit both members. The problem under study has the following features: (1) the supplier can be regarded as the leader whose objective is to maximize his own revenue, whereas the retailer plays the follower striving to maximize the retailer revenue under the supplier's conditions; $(2)$ the supplier is risk-averse, and the retailer is risk-neutral in terms of utility theory; the utility theory approach is different from the MV approach; (3) the supplier's risk preference will be used to determine the charge rate of each unit sold by the retailer, and this rate will be set based on the supplier's CE, so that the supplier believes he still gains no less than his current amount of revenue; (4) the model considers quality risk, which can increase customer satisfaction, maintain company product image, provide an accurate and conservative estimate for the supplier's actual revenue, and thus determine a reliable charge rate. To the best of our knowledge, our approach is the first to combine $\mathrm{CE}$ concept and quality risk for deriving a consignment policy that satisfies both members in a win-win outcome.
This study can be applied to the situation where a supplier has a new short-life or fashion product to enter into the market. Both supplier and retailer have common knowledge of the product's price-sensitive market demand. The supplier is confident of the product's market potential and thus believes that he can serve as the leader in selling the new product. Model 1 can be used for such a business scenario. However, the supplier wishes to create a win-win outcome using a consignment scheme, while considering the risk attitudes of both members in the chain. The CE concept is a useful technique to deal with the supplier's coordination problem. In addition, the inclusion of quality risk will provide the supplier a conservative and more accurate estimate of his total revenue and thus determine a reliable charge rate benefitting both the supplier and the retailer. The proposed consignment scheme is more flexible for the supplier, since he can determine the amount of guaranteed revenue.

The remainder of the paper is organized as follows. Section 2 describes the problem and two models. Section 3 illustrates the method to reduce the quality risk. Section 4 presents numerical results via an example. Section 5 concludes this research.

\section{Description of Models}

Model 1 is a game-theoretic type, where both supplier and retailer have their own decision powers in a market. The supplier can determine the wholesale price, whereas the retailer will respond with a market price and an order quantity that maximize his own revenue. The bargaining process ends when the supplier has found a wholesale price that maximizes the value of his sales revenue minus the product quality cost. It is assumed that the retailer has full knowledge on how the market price will influence the mean of the market demand distribution, but not the variance.

In this model, the supplier earns his revenue solely from order quantity but must bear the cost of defective products sold to customers. On the other hand, the retailer undertakes market risks such as overage cost and shortage cost. To reduce quality risk, the supplier will employ a Bayesian double sampling inspection model to minimize product quality cost.

Model 2 uses a consignment contract where the charge rate is devised based on the supplier's utility function, given that the retailer is willing to forgo his market decision power in order to obtain a better trade-off. In Model 2, the supplier determines market price and product supply quantity but will share market risk. The retailer will play the role of selling products and earns revenue based on the charge rate.

\section{Notations}

$\omega$ : supplier selling price per unit; $\omega \in \Omega=\left[\omega_{L}, \omega_{U}\right]$

$\tau$ : market price

$q$ : order quantity by the retailer

$X(\tau)$ : stochastic demand when market price is $\tau$; $X(\tau) \sim N\left(\mu(\tau), \sigma^{2}\right)$

$\mu(\tau)$ : mean demand quantity, a linear function of $\tau$ : $\mu(\tau)=a-b \cdot \tau$ 
$s$ : salvage value per unit

$B$ : shortage cost per unit

$c$ : production cost per unit

$q_{1}(\omega)$ : optimal order quantity based on $\omega$ in Model 1

$\tau_{1}(\omega)$ : optimal market price based on $\omega$ in Model 1

$q_{2}(\tau)$ : optimal supply quantity based on $\tau$ in Model 2

$\operatorname{RR}_{m}(\eta)$ : retailer revenue of Model $m$ with parameter $\eta, m=1,2$

$\operatorname{SR}_{m}(\eta)$ : supplier market revenue of Model $m$ with parameter $\eta, m=1,2$

$\mathrm{QC}_{m}(\eta)$ : expected quality cost with parameter $\eta, m=$ 1,2

$\operatorname{NSR}_{m}(\eta)$ : net supplier revenue of Model $m$ with parameter $\eta, m=1,2$

$\mathrm{TR}_{m}(\eta)$ : total supply chain revenue of Model $m$ with parameter $\eta, m=1,2$

$\operatorname{NTR}_{m}(\eta)$ : net supply chain revenue of Model $m$ with parameter $\eta, m=1,2$

$U(x)$ : utility value of revenue $x$

$\rho$ : charge rate (fraction of market price per unit sold for the supplier)

GM: amount of guaranteed money that the supplier receives.

2.1. Model 1. The market relationships among the three parties of Model 1 are shown in Figure 1. The supplier seeks an optimal $\omega$ that maximizes the value of the sales revenue minus the quality cost. In response, the retailer strives to find the optimal market price $\tau_{1}(\omega)$ and optimal order quantity $q_{1}(\omega)$ that will maximize his expected revenue, denoted by $\mathrm{RR}_{1}(\omega)$. Figure 1 exhibits the relationships among the parties.

The retailer revenue $\mathrm{RR}$ for a market parameter setting $(\tau, \omega, q)$ can be expressed as follows:

$$
\begin{aligned}
\operatorname{RR}(\tau, \omega, q)= & \tau \cdot E(\operatorname{Min}(q, X(\tau)))-\omega \cdot q \\
& +s \cdot E(q-X(\tau))^{+}-B \cdot E(q-X(\tau))^{-}
\end{aligned}
$$

where $(q-X(\tau))^{+}=\operatorname{Max}\{q-X(\tau), 0\}$ and $(q-X(\tau))^{-}=$ $\operatorname{Max}\{X(\tau)-q, 0\}$.

To find the optimal values $\left(q_{1}(\omega), \tau_{1}(\omega)\right)$ and to obtain optimal retailer revenue $\mathrm{RR}_{1}(\omega)$, we first differentiate the formula (1) with respect to $q$ and then check the first- and second-order conditions. The results indicate that there exists a global optimal solution $q^{*}(\tau, \omega)$ which satisfies (2). By assuming that the market price $\tau$ is a multiple of a certain number (e.g., dollars or half dollars), the optimal market price $\tau_{1}(\omega)$ can easily be computed using (3) as follows:

$$
\begin{gathered}
q^{*}(\tau, \omega)=F^{-1}\left(\frac{\tau-\omega+B}{\tau-s+B}\right), \\
\tau_{1}(\omega)=\{\tau \mid(\tau, \omega) \text { maximizes }(1): \tau>\omega\} .
\end{gathered}
$$

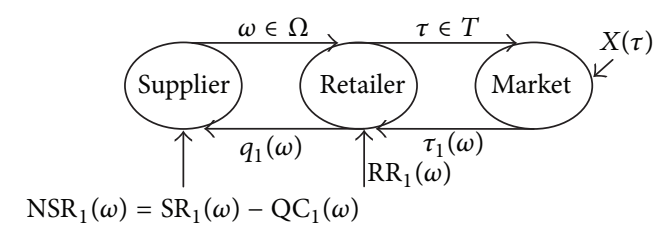

FIGURE 1: Relationships of supply chain parties in Model 1.

For simplicity, we use notation $q_{1}(\omega)=q^{*}\left(\tau_{1}(\omega), \omega\right)$, which is the optimal order quantity with respect to $\omega$. The value $\operatorname{RR}_{1}(\omega)$ will then be calculated (1) using $\left(\tau_{1}(\omega), \omega\right.$, $q_{1}(\omega)$ ), and the net supplier revenue is given in (4) as follows:

$$
\operatorname{NSR}_{1}(\omega)=\operatorname{SR}_{1}(\omega)-\mathrm{QC}_{1}(\omega)
$$

where $\operatorname{SR}_{1}(\omega)=(\omega-c) \cdot q_{1}(\omega)$ and $\mathrm{QC}_{1}(\omega)$ is the product quality cost for $q_{1}(\omega)$ units calculated using the Bayesian double sampling inspection model (see Section 3). Thus, the optimal expected revenue of the supplier can be calculated using (5), and the supplier will select the corresponding wholesale price $\omega^{*}$ as follows:

$$
\operatorname{NSR}_{1}\left(\omega^{*}\right)=\operatorname{Max}\left\{\operatorname{NSR}_{1}(\omega) \mid \omega \in \Omega\right\} .
$$

The following describes the procedure for obtaining optimal decisions.

$$
\text { Input: } \Omega, \mathrm{T},\{X(\tau) \mid \tau \in \mathrm{T}\}, c, B \text {. }
$$

Step 1: Select $\omega \in \Omega, \Omega=\Omega-\{\omega\}$; find $\left(q_{1}(\omega), \tau_{1}(\omega)\right)$ among all $\tau \in \mathrm{T}$ using (1), (2), (3); note that $q_{1}(\omega)=$ $q^{*}\left(\tau_{1}(\omega), \omega\right)$ is the order quantity with respect to the market price that maximizes $\operatorname{RR}_{1}(\omega)$.

Step 2: Compute $\operatorname{SR}_{1}(\omega)=(\omega-c) \cdot q_{1}(\omega)$; apply sampling inspection to $q_{1}(\omega)$ and calculate the quality cost $\mathrm{QC}_{1}(\omega)$; compute $\mathrm{NSR}_{1}(\omega)$ with (4).

Step 3: Repeat Steps 1 and 2 until $\Omega=\phi$; find $\operatorname{NSR}_{1}\left(\omega^{*}\right)$ using (5).

$$
\text { Output: } \operatorname{NSR}_{1}\left(\omega^{*}\right), \operatorname{RR}_{1}\left(\omega^{*}\right), \tau_{1}^{*}\left(\omega^{*}\right), q_{1}\left(\omega^{*}\right), \omega^{*} \text {. }
$$

As a summary of Model 1, the supplier will offer the wholesale price $\omega^{*}$ satisfying (5) and the retailer will respond with $\left(\tau_{1}\left(\omega^{*}\right), q_{1}\left(\omega^{*}\right)\right)$ and will get revenue by substituting these two values into (1). Figure 4 presents the results of retailer revenue $\mathrm{RR}$ with respect to various market prices $\tau$ for a constant $\omega=58$. The market price $\tau=79$ produces the maximum retailer revenue $\left(\mathrm{RR}_{1}(\omega=58)\right)$. When there are several wholesale prices of $\omega$ corresponding to the same market price $\tau$, the one with the maximum supplier revenue will be chosen. Table 1 displays the results of the example with the same parameters used in Figure 4. In the example, the wholesale prices $\omega=\{56,57,58\}$ correspond to the same optimal market price $\tau=79$. The value 58 generates the maximum revenue for the supplier, and therefore, the pair $\left(\omega, \tau_{1}(\omega)\right)=(58,79)$ is chosen. Figure 5 depicts supplier revenue, retailer revenue, and optimal order quantity with respect to each market price $\tau$ on the same example. 


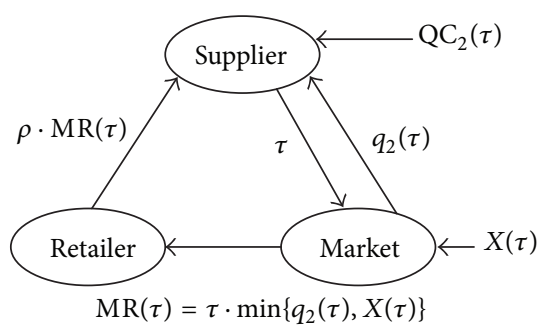

FIgURE 2: Model 2 with consignment policy.

2.2. Model 2. In this model, the supplier is able to determine market price $\tau$ and production (or supply) quantity $q$ to meet the market demand $X(\tau)$, with the tradeoff of sacrificing a certain amount of guaranteed revenue and undertaking a portion of market risk. In contrast, the retailer forgoes his decision power on $\tau$ and $q$ for certain benefits, such as higher expected revenue with reduced market risk. This research proposes a coordination scheme using consignment contractual concept, meaning that the retailer will earn a fraction of market price $(1-\rho) \cdot \tau$ for each unit sold. Figure 2 presents the relationships among the parties in Model 2. Based on this assumption, the total supply chain revenue $\mathrm{TR}_{2}(\tau)$, given a production quantity $q$, excluding the quality cost, satisfies (6). After several algebraic operations, the optimal production quantity can be expressed as in (7). The maximum total supply chain revenue $\mathrm{TR}_{2}(\tau)$ is then calculated using $q=q_{2}(\tau)$ in (6) as follows:

$$
\begin{aligned}
\operatorname{TR}_{2}(\tau) \mid q= & \tau \cdot E(\operatorname{Min}(q, X(\tau)))-c \cdot q \\
+ & s \cdot E(q-X(\tau))^{+}-B \cdot E(q-X(\tau))^{-}, \\
& q_{2}(\tau)=F^{-1}\left(\frac{\tau-c+B}{\tau-s+B}\right) .
\end{aligned}
$$

Since $(\tau-c+B) /(\tau-s+B)>(\tau-\omega+B) /(\tau-s+B)$ for $\tau>\omega>$ $c$, the supply quantity of Model 2 is greater than that of Model 1 for each $\tau=\tau_{1}(\omega)$. If $\operatorname{NTR}_{2}\left(\tau_{1}(\omega)\right)>\operatorname{NTR}_{1}(\omega)$, then there exists one or more win-win alternative. Table 2 presents the results of Models 1 and 2 using the same example of Table 1. For each market price $\tau_{1}(\omega), \operatorname{NTR}_{2}\left(\tau_{1}(\omega)\right)>\operatorname{NTR}_{1}(\omega)$. In Model 1, the supplier will determine $\omega^{*}=58$ and the retailer responds with $\tau_{1}\left(\omega^{*}\right)=79$. The decisions generate the net supplier revenue $\mathrm{NSR}_{1}\left(\omega^{*}\right)=41552$ and the retailer revenue $\mathrm{RR}_{1}\left(\omega^{*}\right)=20492$ (see Table 1). From Table 2, we observe that the alternatives of $\tau$ from 71 to 79 are win-win feasible since both parties have expected revenues greater than what they will obtain in Model 1. The objective of this research is to resolve the revenue-sharing problem that arises from converting the business operation pattern from Model 1 to Model 2. Section 2.3 will introduce our proposed solution procedure.

2.3. Consignment Policy Based on Supplier Risk-Attitude. We present a solution approach combining utility theory and consignment policy for the revenue sharing conflict.
In Model 1, the supplier will receive maximum guaranteed revenue from the retailer based on optimal order quantity. The supplier will not bear any market risk. If the supplier is a risk-averse decision maker, as are most people, he will not compromise based solely on expected revenue. A risk-averse decision maker will prefer guaranteed $x$ dollars to expected $x$ dollars and small variance (less uncertainty) to large variance. The following is the proposed consignment policy formula based on certainty equivalent in utility theory:

$$
\begin{aligned}
u(y)=\int_{0}^{q} u(\mathrm{GM}+\rho \cdot \tau \cdot x-c \cdot q \\
\left.+s(q-x)-\mathrm{QC}_{2}(q)\right) \cdot f(x) d x \\
+\int_{q}^{\infty} u(\mathrm{GM}+\rho \cdot \tau \cdot q-c \cdot q) \\
\quad-B(x-q)-\mathrm{QC}_{2}(q) \cdot f(x) d x,
\end{aligned}
$$

where $u(\cdot)$ is the supplier's utility function, GM is the amount of guaranteed money that the supplier receives, and $\mathrm{QC}_{2}(q)$ is the quality cost for supplying optimal order quantity $q$ units to customers. The value $\mathrm{QC}_{2}(q)$ can be approximated by an affine function of $q$ based on experimental data. While calculating the charge rate $\rho, \mathrm{QC}_{2}(q)$ will be treated as a constant since $\rho$ is more concerned with market risk and the computational complexity will also be greatly reduced. The fundamental concept of this approach is certainty equivalent, meaning that the utility value on the left of the equation must be equal to that on the right. This certainty equivalent implies that the supplier is indifferent to the received revenue on both sides of the equation, although the revenue on the right of the equation involves market risk. Clearly, as GM increases, the value of $\rho$ will decrease. The value of $\rho$ can be interpreted as the minimum fraction of $\tau$ that the supplier is willing to pay for sharing the market risk, given GM.

If the utility function is linear, then the decision maker is risk-neutral and he will make a decision based on expected monetary value (EMV). If the risk premium EMV - $y$ is positive, then the decision maker is risk-averse. As for the choice of utility function regarding risk-averse attitude, two types are often used: constantly risk-averse and decreasingly risk-averse. The former type implies that the decision maker will not change his risk attitude regardless of his wealth, whereas the latter type implies that the decision maker will decrease his risk aversion as his wealth increases. If the supplier is constantly risk-averse, he can use the following exponential utility functions: $u(x)=1-\exp (-x / R)$, where $R$ is risk tolerance. The smaller the risk tolerance value $R$, the stronger the risk-averse attitude. Some utility functions for decreasingly risk-averse attitude are the following: $\operatorname{Ln}(C+x)$, $x^{1 / 3}$, and so forth.

In the following, we propose a decision procedure for determining $(\mathrm{GM}, \rho)$ when both parties agree to operate business using Model 2. Note that in Model 1, the supplier will receive guaranteed revenue from retailer and the quality cost is considered as a constant to simplify the computational complexity. 
TABLE 1: Numerical results for $\omega$ in $[48,59]$ of Model 1 example.

\begin{tabular}{|c|c|c|c|c|c|c|c|}
\hline$\tau_{1}(\omega)$ & $\omega$ & $q_{1}(\omega)$ & $\mathrm{QC}_{1}(\omega)$ & $\operatorname{SR}_{1}(\omega)$ & $\operatorname{NSR}_{1}(\omega)$ & $\mathrm{RR}_{1}(\omega)$ & $\mathrm{TR}_{1}(\omega)$ \\
\hline 75 & 48 & 1239 & 2097 & 40887 & 38790 & 32708 & 71498 \\
\hline 75 & 49 & 1235 & 2090 & 41990 & 39900 & 31376 & 71276 \\
\hline 76 & 50 & 1183 & 2003 & 41405 & 39402 & 30034 & 69436 \\
\hline 76 & 51 & 1179 & 1996 & 42444 & 40448 & 28770 & 69218 \\
\hline 77 & 52 & 1127 & 1909 & 41699 & 39790 & 27480 & 67270 \\
\hline 77 & 53 & 1122 & 1901 & 42636 & 40735 & 26242 & 66977 \\
\hline 78 & 54 & 1071 & 1815 & 41769 & 39954 & 25022 & 64976 \\
\hline 78 & 55 & 1066 & 1807 & 42640 & 40834 & 23860 & 64694 \\
\hline 79 & 56 & 1014 & 1719 & 41574 & 39855 & 22674 & 62529 \\
\hline 79 & 57 & 1010 & 1712 & 42420 & 40708 & 21568 & 62275 \\
\hline 79 & 58 & 1006 & 1706 & 43258 & 41552 & 20492 & 62045 \\
\hline 80 & 59 & 954 & 1618 & 41976 & 40358 & 19410 & 59767 \\
\hline
\end{tabular}

The bold values refer to the results of local optimal wholesale prices, and the bold italic value denotes the results of the global optimal wholesale price $\omega^{*}=58$.

TABLE 2: Comparative results between Models 1 and 2 based on $\tau$.

\begin{tabular}{lccccc}
\hline$\tau$ & $\mathrm{RR}_{1}$ & $\mathrm{NSR}_{1}$ & $\mathrm{NTR}_{2}$ & $\mathrm{NTR}_{2}-\mathrm{RR}_{1}$ & $\mathrm{NTR}_{2}-\mathrm{NSR}_{1}-\mathrm{RR}_{1}$ \\
\hline 70 & 47850 & 32476 & 87562 & 39712 & 7236 \\
71 & 44591 & 34195 & 86574 & 41983 & 7788 \\
72 & 41454 & 35686 & 85488 & 44034 & 8348 \\
73 & 36955 & 8460 & 83022 & 47349 & 9189 \\
74 & 34124 & 39158 & 81642 & 58898 & 10366 \\
75 & 31376 & 40448 & 80111 & 50266 & 10893 \\
76 & 28770 & 40735 & 78534 & 52292 & 11557 \\
77 & 26242 & 40834 & 76859 & 52999 & 12165 \\
78 & 23860 & 41552 & 75068 & 54576 & 13024 \\
80 & 20492 & 40358 & 73196 & 53786 & 13428 \\
\hline
\end{tabular}

Step 1. Compute $\left(\operatorname{NSR}_{1}(\omega), \tau_{1}(\omega), \mathrm{RR}_{1}(\omega)\right)$ for $\omega \in \Omega$ and find optimal $\omega^{*}$ in Model 1. For convenience to compare Models 1 and 2, we also express the results of Model 1 based on market price. For example, in Table 1, $\tau=77$ corresponds to $\omega=53, \mathrm{RR}_{1}=26242, \mathrm{NSR}_{1}=40735$, and so forth.

Step 2. Compute $\left(\mathrm{TR}_{2}(\tau), \mathrm{NTR}_{2}(\tau), q_{2}(\tau)\right) \cdot \operatorname{NTR}_{2}(\tau)=$ $\mathrm{TR}_{2}(\tau)-\mathrm{QC}_{2}\left(q_{2}(\tau)\right)$ for each $\tau$. Then, we define $\operatorname{NSR}_{2}(\tau)=$ $\mathrm{NTR}_{2}(\tau)-\mathrm{RR}_{1}(\tau)$. In Table $2, \mathrm{NTR}_{2}-\mathrm{RR}_{1}$ represents the maximum revenue that the supplier will obtain if the retailer insists that his reasonable revenue will at least be the same as that in Model 1. For example, when $\tau=77, \mathrm{RR}_{1}=26242$ and $\mathrm{NSR}_{2}=\mathrm{NTR}_{2}-\mathrm{RR}_{1}=52292$; when $\tau=79, \mathrm{RR}_{1}=20492$ and $\mathrm{NSR}_{2}=54576$. The last column of Table 2 indicates the difference between the total supply chain revenues of the two models. The two values increase as $\tau$ increases, although $\mathrm{NTR}_{2}$ decreases as $\tau$ increases.

Step 3. Find the set of win-win alternatives, each of which generates better revenues compared to what both parties will obtain in Model 1 in terms of EMV. For example, in Table 2, the alternatives of $\tau$ values between 71 and 79 satisfy this condition.

Step 4. For these feasible alternatives, calculate the charge rate $\rho$ for each alternative using the corresponding guaranteed revenue and no guaranteed revenue.

Step 5. All alternatives with corresponding charge rate $\rho$ are the same to the supplier in terms of his utility function. Meanwhile, the retailer will not be against these alternatives since he will earn higher expected revenue than in Model 1. If the supplier has the right of selecting one of them and the criterion is based on expected value and standard deviation, then the alternative with minimum coefficient of variation (CV) should be chosen. $\mathrm{CV}$ refers to $\sigma / \mu$, the ratio of standard deviation over expected value.

\section{Minimizing Quality Cost}

In both models, the supplier must bear the cost of defective products sold to customers. To reduce quality risk, 


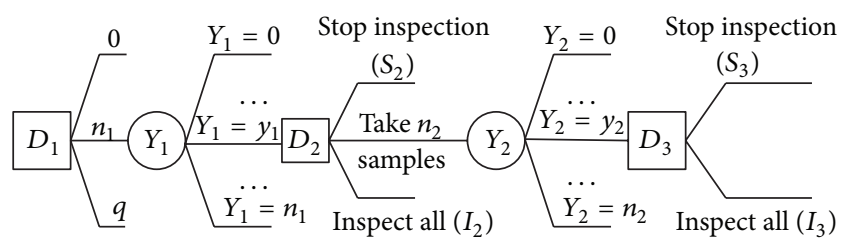

Figure 3: Decision tree for the double sampling plan.

the supplier will employ a Bayesian double sampling inspection model to minimize product quality cost.

\section{Notations}

$k_{1}$ : inspection cost per unit

$k_{2}$ : product failure cost per unit

$P$ : probability of a unit product being non-defective, assumed to be Beta $(\alpha, \beta)$

$D_{1}$ : first stage decision, aiming to determine the optimal inspection sample size $n_{1}$

$D_{2}$ : second stage decision, deciding: (1) stop inspection, (2) take $n_{2}$ samples, and (3) inspect all the remaining units

$D_{3}$ : third stage decision, which is required only if $D_{2}=n_{2}>0$ samples

$Y_{k}$ : sampling outcome at the $k$ th stage, $k=1,2$; two random variables

$Z_{m}$ : number of defectives in $m$ units; a random variable

$M\left(Y_{k}\right)$ : number of inspections to obtain $Y_{k}$ good units, $k=1,2$; two random variables.

After receiving the ordered quantity, the supplier will perform inspection before shipping the units to the retailer. Figure 3 shows the decision tree that represents the inspection sampling model used by the supplier. The first stage decision $D_{1}$ is to select a sample size $n_{1}, 0 \leq n_{1} \leq q$. After observing the sampling outcome $\left(n_{1}, y_{1}\right)$, the second stage decision $D_{2}$ will take one of the following three actions: (1) stop inspection of the remaining $q-n_{1}$ units (denoted by $S_{2}$ ); (2) take $n_{2}$ additional samples; and (3) inspect the remainder (denoted by $I_{2}$ ). If $D_{2}$ is to take $n_{2}$ samples, then $D_{3}$ will take either $S_{3}$ or $I_{3}$, depending on the total outcome $\left(n_{1}+n_{2}, y_{1}+y_{2}\right)$.

The total objective function of the double inspection sampling model can be derived based on the decision tree theory. At stage 3 , given sampling information $\left(n_{1}, n_{2}, y_{1}, y_{2}\right)$, the expected cost due to decision $\left\{D_{3}=S_{3}\right\}$ is as follows:

$$
\begin{aligned}
E\left(D_{3}=\right. & \left.S_{3} \mid n_{1}, n_{2}, y_{1}, y_{2}\right) \\
= & E\left[M\left(y_{2}\right)+M\left(Z_{q-n_{1}-n_{2}}\right) \mid\left(n_{1}+n_{2}, y_{1}+y_{2}\right)\right] \cdot k_{1} \\
& +E\left(Z_{q-n_{1}-n_{2}} \mid n_{1}+n_{2}, y_{1}+y_{2}\right) \cdot k_{2} .
\end{aligned}
$$

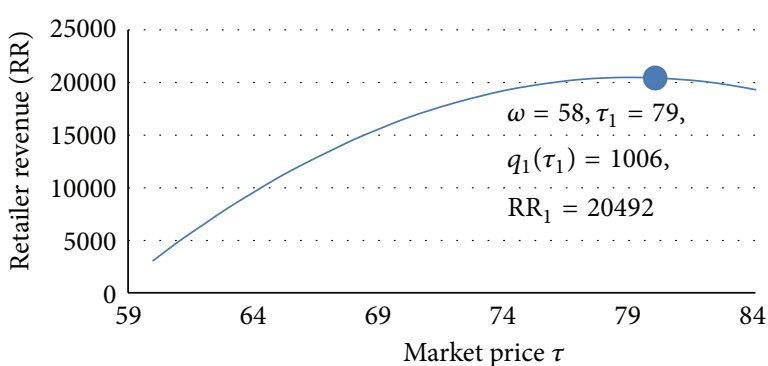

FIGURE 4: Retailer revenues for $\tau$ given $\omega=58$ of Model 1 example.

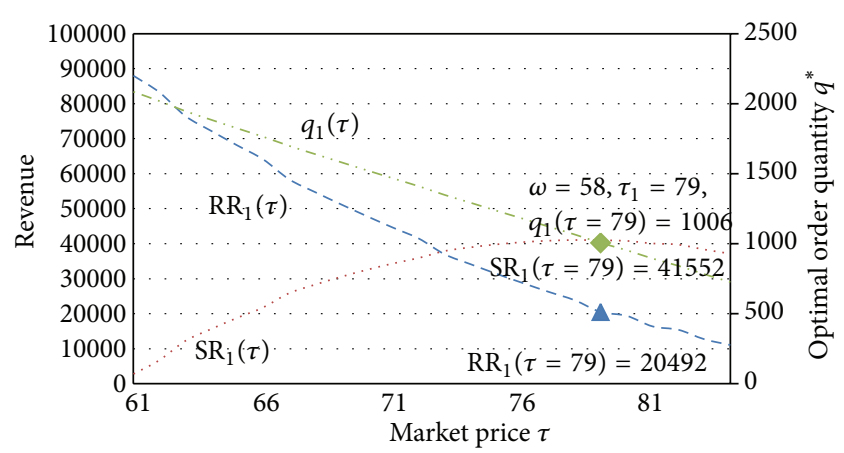

FIgURE 5: Numerical results of both parties with respect to $\tau$ for Model 1 example.

The expected cost due to decision $\left\{D_{3}=I_{3}\right\}$ is as follows:

$$
\begin{aligned}
E\left(D_{3}=\right. & \left.I_{3} \mid n_{1}, n_{2}, y_{1}, y_{2}\right) \\
= & E\left[M\left(y_{2}\right)+M\left(Z_{\mathrm{Q}-n_{1}-n_{2}}\right) \mid\left(n_{1}+n_{2}, y_{1}+y_{2}\right)\right] \cdot k_{1} \\
& +\left(Q-n_{1}-n_{2}\right) \cdot k_{1} .
\end{aligned}
$$

Decision $\left\{D_{3}=S_{3}\right\}$ is better than $\left\{D_{3}=I_{3}\right\}$ if the following conditions hold:

$$
E\left(Z_{q-n_{1}-n_{2}} \mid n_{1}+n_{2}, y_{1}+y_{2}\right) \cdot k_{2} \leq\left(q-n_{1}-n_{2}\right) \cdot k_{1} .
$$

At stage 2 with information $\left(n_{1}, y_{1}\right)$, there are three alternatives, $\left(S_{2}, n_{2}, I_{2}\right)$ :

$$
\begin{aligned}
E\left(D_{2}=S_{2} \mid n_{1}, y_{1}\right)= & E\left[M\left(y_{1}\right)+M\left(Z_{q-n_{1}}\right) \mid n_{1}, y_{1}\right] \\
& \cdot k_{1}+E\left(Z_{q-n_{1}} \mid n_{1}, y_{1}\right) \cdot k_{2}, \\
E\left(D_{2}=I_{2} \mid n_{1}, y_{1}\right)= & E\left[M\left(y_{1}\right)+M\left(Z_{q-n_{1}}\right) \mid n_{1}, y_{1}\right] \\
\cdot & k_{1}+\left(q-n_{1}\right) \cdot k_{1},
\end{aligned}
$$




$$
\begin{aligned}
& E\left(D_{2}=n_{2} \mid n_{1}, y_{1}\right)= E\left[M\left(y_{1}\right) \mid n_{1}, y_{1}\right] \cdot k_{1} \\
&+\sum_{y_{2}=0}^{n_{2}} \operatorname{Min}\left[E\left(S_{3} \mid n_{1}, n_{2}, y_{1}, y_{2}\right),\right. \\
&\left.E\left(I_{3} \mid n_{1}, n_{2}, y_{1}, y_{2}\right)\right] \\
& \cdot \operatorname{Pr}\left\{Y_{2}=y_{2} \mid n_{1}, n_{2}, y_{1}\right) .
\end{aligned}
$$

The optimal expected cost at stage 1 satisfies the following equation:

$$
\begin{aligned}
\operatorname{Min}_{0 \leq n_{1} \leq Q}\left(n_{1} \cdot k_{1}+\sum_{y_{1}=0}^{n_{1}} \operatorname{Min}\left[E\left(S_{2} \mid n_{1}, y_{1}\right),\right.\right. \\
\left.E\left(n_{2} \mid n_{1}, y_{1}\right) E\left(I_{2} \mid n_{1}, y_{1}\right)\right) \cdot \operatorname{Pr}\left(y_{1} \mid n_{1}\right) .
\end{aligned}
$$

Some specific formulae in calculating the above equations are shown as follows: $E\left(Z_{m} \mid n, y\right)=m \cdot(1-E(P \mid n, y))$, $(M(y) \mid n, y)=y \cdot E(1 / P \mid n, y), E\left(M\left(Y_{k}\right) \mid n, y\right)=E\left(Y_{k}\right)$. $(E(1 / P \mid n, y)-1)$, and if $P \sim \operatorname{Beta}(\alpha, \beta)$, then $E(P \mid n, y)=$ $(\alpha+n-y) /(\alpha+\beta+n)$ and $E(1 / P \mid n, y)=(\alpha+\beta+n-1) /(\alpha+$ $n-y-1)$.

For double sampling, $n_{1}$ is the first stage sample size and $c_{1}$ is the interval at which it decides to take one of the three actions: stop inspection, take $n_{2}$ samples, and inspect all. The number $c_{2}$ is the upper bound criterion to stop inspection. To reduce the computation complexity, the sample size $n_{2}$ is between $10 \%$ and $50 \%$ of $n_{1}$ and increases by a size of 5 at each step of computation.

We performed a number of experiments for single sampling and concluded the following: the expected cost function is not convex in terms of sample size. The function locally behaves in a wiggly fashion with slight vertical fluctuations, although it appears to be globally convex. Thus, we develop an efficient heuristic to seek the optimal sample size for the double sampling plan described above.

\section{Illustrative Example}

4.1. Numerical Results of Model 1. The following example illustrates Model 1 with parameters set to the following values: production cost $c=15, \omega>c$ and $\tau \geq \omega+1, s=10, B=6$, $\mu(\tau)=a-b \cdot \tau$ with $(a, b)=(5000,50), \sigma=125, k_{1}=1$, $k_{2}=30$, and $P \sim \operatorname{Beta}(\alpha=19, \beta=1)$.

Figure 4 presents retailer revenue as a function of $\tau$ for $\omega=58$. This is the optimal $\omega$ value using the procedure in Section 2.1. Table 1 displays the neighboring results of $\omega=58$. Table 1 shows the optimal values of market price, retailer revenue, and order quantity for $\omega$ from 48 to 59 . Computational results indicate that there could be several $\omega$ 's corresponding to same $\tau$. In this situation, the one that produces the maximum retailer revenue is chosen. In this example, the wholesale prices $\omega=\{56,57,58\}$ have the same $\tau=79$. Furthermore, the supplier will obtain maximum revenue $\operatorname{NSR}_{1}(\omega)=41552$ at $\omega=58$, and thus $\omega^{*}=58$,
TABLE 3: Results of double inspection sampling plan.

\begin{tabular}{lccccc}
\hline \multirow{5}{*}{$q$} & \multicolumn{4}{c}{ Double sampling plan } \\
& $n_{1}$ & $c_{1}$ & $n_{2}$ & $c_{2}$ & Quality cost \\
\hline 1000 & 109 & {$[1,3]$} & 34 & 4 & 1562 \\
800 & 94 & {$[1,3]$} & 28 & 4 & 1282 \\
600 & 82 & {$[0,2]$} & 22 & 3 & 924 \\
\hline
\end{tabular}

$\tau_{1}\left(\omega^{*}\right)=79, q_{1}\left(\omega^{*}\right)=1006$, and $\mathrm{RR}_{1}\left(\omega^{*}\right)=20492$. Figure 5 displays all relevant results of this example when Model 1 is applied.

Table 3 provides numerical results of the Bayesian double sampling inspection plan for the case that $k_{1}=1, k_{2}=30$, and $P \sim \operatorname{Beta}(19,1)$. For the example of $n=1000$, the first stage sample size is $n_{1}=109$. If the number of defectives $y_{1}$ is zero, stop inspection; if $1 \leq y_{1} \leq 3$, then go to the third stage and take $n_{2}=34$ samples; if $y_{1} \geq 4$, inspect all the remaining units. When taking $n_{2}$ samples, if $y_{1}+y_{2} \leq 4$, stop inspection; otherwise, continue to inspect all.

\subsection{Determining the Charge Rate $\rho$ for the Consignment Policy.} This section describes the procedure of determining the charge rate $\rho$ through an example. Table 2 lists the numerical results based on the same parameter settings in Section 4.1 and the resultant results in Model 1. For simplicity, we omit the parameter associated with each notation as given in Section 2. In Table 2, both parties acquire higher revenues than in Model 1 for market prices between 71 and 79. The last column lists the additional revenue of the supplier if the retailer keeps the same expected revenue as in Model 1. It is observed that the additional supplier revenue increases as market price increases from 7788 to 13024 . However, the retailer will not believe that the deal of market price $\tau=$ 79 is fair to him, since the supplier will acquire the same amount of guaranteed money plus a significantly additional amount of expected revenue. In contrast, the retailer retains the earning of the same expected revenue but his market risk is actually higher than that in Model 1. One means to resolve this dilemma is that the retailer will earn higher revenue with smaller standard deviation. Meanwhile, the supplier will substantially gain more than in Model 1. The CE concept in the utility theory may be one of the best methods to be applied to resolve the supplier's decision dilemma. In addition, adopting the consignment policy will reduce the retailer's market risk, as this strategy will induce the supplier to get involved in sharing the market risk with the retailer.

According to Step 4 of Section 2.3, (8) is applied to calculate the charge rate $\rho$ for the feasible alternatives shown in Table 2. Tables 4 and 5 present the $\rho$ values for $R=$ 30000. Table 4 shows the results with no guaranteed revenue, whereas Table 5 displays the $\rho$ values with guaranteed revenue corresponding to each alternative. It should be noted that all feasible alternatives with corresponding charge rate $\rho$ are same to the supplier in terms of his utility function. Meanwhile, the retailer will not be against these alternatives since he will earn higher expected revenue with lower variance than that in Model 1. 
TABLE 4: Revenue sharing based on $R=30000$ and $\mathrm{GM}=0$.

\begin{tabular}{lcccccccccc}
\hline$\tau$ & $q_{2}(\tau)$ & $\mathrm{RR}_{1}$ & $\mathrm{NSR}_{1}$ & $\mathrm{NTR}_{2}$ & $\rho$ & $\mathrm{RR}_{2}$ & $\mathrm{NSR}_{2}$ & $\mathrm{NSR}_{2}-\mathrm{NSR}_{1}$ & std $\left(\mathrm{NSR}_{2}\right)$ & $\left.\mathrm{CV}_{(\mathrm{NSR}}\right)$ \\
\hline 71 & 1467 & 44591 & 34195 & 86574 & 0.66 & $\mathbf{2 9 4 3 5}$ & $\mathbf{5 7 1 3 9}$ & 22944 & 7253 & 0.127 \\
72 & 1410 & 41454 & 35686 & 85488 & 0.70 & $\mathbf{2 5 6 4 6}$ & $\mathbf{5 9 8 4 2}$ & 24156 & 7221 & $\mathbf{0 . 1 2 1}$ \\
73 & 1348 & 36955 & 38160 & 84304 & 0.77 & 19390 & 64914 & 26754 & 7153 & 0.112 \\
74 & 1292 & 34124 & 39158 & 83022 & 0.81 & 15774 & 67248 & 28090 & 7142 & 0.106 \\
75 & 1235 & 31376 & 39900 & 81642 & 0.85 & 12246 & 69396 & 29496 & 6988 & 0.101 \\
76 & 1179 & 28770 & 40448 & 80111 & 0.88 & 9613 & 70498 & 30050 & 6778 & 0.096 \\
77 & 1122 & 26242 & 40735 & 78534 & 0.91 & 7068 & 71466 & 30731 & 6531 & 0.091 \\
78 & 1066 & 23860 & 40834 & 76859 & 0.92 & 6149 & 70710 & 29876 & 6211 & 0.088 \\
79 & 1006 & $\mathbf{2 0 4 9 2}$ & $\mathbf{4 1 5 5 2}$ & 75068 & 0.93 & 5255 & 69813 & 28261 & 5784 & 0.083 \\
\hline
\end{tabular}

The bold values refer to the results of local optimal wholesale prices, and the bold italic value denotes the results of the global optimal wholesale price $\omega^{*}=58$.

TABLE 5: Revenue sharing based on $R=30000$ and $G M=\mathrm{NSR}_{1}$.

\begin{tabular}{lcccccccccc}
\hline$\tau$ & $q_{2}(\omega)$ & $\mathrm{RR}_{1}$ & $\mathrm{NSR}_{1}$ & $\mathrm{NTR}_{2}$ & $\rho$ & $\mathrm{RR}_{2}$ & $\mathrm{NSR}_{2}$ & $\mathrm{NSR}_{2}-\mathrm{NSR}_{1}$ & std $\left(\mathrm{NSR}_{2}\right)$ & $\left.\mathrm{CV}_{(\mathrm{NSR}}\right)$ \\
\hline 71 & 1467 & 44591 & 34195 & 86574 & 0.28 & $\mathbf{2 8 1 3 8}$ & $\mathbf{5 8 4 3 6}$ & 24241 & 4720 & 0.081 \\
72 & 1410 & 41454 & 35686 & 85488 & 0.29 & $\mathbf{2 5 0 1 1}$ & $\mathbf{6 0 4 7 7}$ & 24791 & 4644 \\
73 & 1348 & 36955 & 38160 & 84304 & 0.32 & 19167 & 65137 & 26977 & 4572 \\
74 & 1292 & 34124 & 39158 & 83022 & 0.33 & 16467 & 66555 & 27397 & 4555 & 0.077 \\
75 & 1235 & 31376 & 39900 & 81642 & 0.35 & 13168 & 68474 & 28574 & 4480 & 0.068 \\
76 & 1179 & 28770 & 40448 & 80111 & 0.36 & 10823 & 69288 & 28840 & 4332 \\
77 & 1122 & 26242 & 40735 & 78534 & 0.36 & 9526 & 69008 & 28273 & 4161 & 0.063 \\
78 & 1066 & 23860 & 40834 & 76859 & 0.36 & 8356 & 68503 & 27669 & 3882 \\
79 & 1006 & $\mathbf{2 0 4 9 2}$ & $\mathbf{4 1 5 5 2}$ & 75068 & & & & & 0.057 \\
\hline
\end{tabular}

The bold values refer to the results of local optimal wholesale prices, and the bold italic value denotes the results of the global optimal wholesale price $\omega^{*}=58$.

TABLE 6: Effects of product quality $P$ on $\rho$ for $\mathrm{GM}=0$.

\begin{tabular}{lccc}
\hline & & $P$ & \\
$\tau$ & Beta $(49,1)$ & Beta $(19,1)$ & Beta $(23,2)$ \\
& $E(P)=0.98$ & $E(P)=0.95$ & $E(P)=0.92$ \\
\hline 71 & 0.66 & 0.66 & 0.64 \\
75 & 0.86 & 0.85 & 0.82 \\
78 & 0.93 & 0.92 & 0.89 \\
\hline
\end{tabular}

TABLE 7: Effects of product failure cost $k_{2}$ on $\rho$ for $\mathrm{GM}=0$.

\begin{tabular}{lccc}
\hline$\tau$ & \multicolumn{3}{c}{$k_{2}$} \\
& $k_{2}=20$ & $k_{2}=30$ & $k_{2}=40$ \\
\hline 71 & 0.68 & 0.66 & 0.63 \\
75 & 0.86 & 0.85 & 0.82 \\
78 & 0.93 & 0.92 & 0.9 \\
\hline
\end{tabular}

In the example, if the supplier decides to take GM $=0$ and his risk tolerance is $R=30000$, Table 4 shows that there are only two other feasible alternatives, $\tau=71$ and 72 . All other alternatives have $R_{2}$ values smaller than the $R_{1}=$ 20492 for $\tau=79$. Furthermore, if the supplier has to make a selection, the coefficient of variation $(\mathrm{CV})$, which is defined as $\sigma / \mu$, can be used for comparison. The case $\tau=72$ with $\rho=0.70$ excels since its $\mathrm{CV}=0.121$ is smaller. On the other hand, if the supplier decides to take $\mathrm{GM}=\mathrm{NSR}_{1}$, Table 5 also indicates that three alternatives are feasible, $\tau=71,72$, and 79 .
Likewise, the case $\tau=72$ with $\rho=0.29$ is better than $\tau=71$ with $\rho=0.28$ because the former has a smaller $\mathrm{CV}=0.077$.

Table 6 displays the effects of product quality $P$ on $\rho$ for $\mathrm{GM}=0$, using three distributions of $P: \operatorname{Beta}(49,1)$ with an expected value $E(P)=0.98, \operatorname{Beta}(19,1)$ with $E(P)=0.95$, and $\operatorname{Beta}(23,2)$ with $E(P)=0.92$. The result shows that the charge rate $\rho$ increases as $P$ increases, since the supplier will pay less quality cost when the product quality is high. In addition, the $\rho$ value increases in $\tau$, since the supplier revenue increases and achieves the maximum at $\tau=79$. In contrast, the $\rho$ value decreases as the inspection cost $k_{1}$ and/or product failure cost $k_{2}$ increase, since the supplier's entitled revenue will decline in these situations. Table 7 displays the effect of $k_{2}$ on charge rate $\rho$, which will decrease as $k_{2}$ increases. On the other hand, a high value of $R$ implies that the decision maker is less risk-averse (Table 8 ). Thus, a larger value of $R$ would result in a smaller value of $\rho$. McNamee and Celona [35] provided an approximation formula for calculating $\mathrm{CE}$ of the utility function $1-\exp (x / R): \mathrm{CE}=\mu-0.5 \sigma^{2} / R$, 
TABLE 8: Effects of risk tolerance on $\rho$.

\begin{tabular}{ccccc}
\hline$\tau$ & & $\mathrm{GM}=0$ & & $\mathrm{GM}=\mathrm{NSR}_{1}$ \\
& $R=30000$ & $R=50000$ & $R=30000$ & 0.28 \\
71 & 0.66 & 0.52 & 0.35 & 0.12 \\
75 & 0.85 & 0.62 & 0.36 & 0.13 \\
\hline
\end{tabular}

where $\mu$ and $\sigma^{2}$ are, respectively, the expected value and variance of the payoffs. When the expected value and variance of the total supplier chain are kept the same, the certainty equivalent of the supplier revenue in the consignment policy is approximately $\rho \cdot \mu-0.5(\rho \cdot \sigma)^{2} / R$. When CE of the supplier revenue is kept unchanged, a larger value of $R$ will produce a smaller value of $\rho$.

\section{Conclusions}

This paper studied the supply chain coordination for newsvendor problems when both the supplier and the retailer agree to change the business corporation pattern from Model 1 to Model 2. Model 1 is game theoretic, and Model 2 uses a consignment policy. In Model 1, the supplier owns the decision power of wholesale price, and the retailer determines the market price and order quantity based on the wholesale price and his knowledge of the market price's effects on the market demand. The supplier, in contrast, will bear the product quality risk and adopt a Bayesian rectifying double sampling to reduce quality risk. In Model 1, the supplier will select the wholesale price that maximizes his own benefit, and the retailer will respond with optimal decisions of his own based on the wholesale price.

In general, the expected total supply chain revenue of Model 2 will be greater than that of Model 1, since the former is perfectly coordinated. Therefore, the change of operation pattern is likely to generate a win-win situation for both supply chain members. To find a satisfying compromise solution for the change of business operation, a consignment policy based on two principles is devised. First, the retailer will receive higher expected revenue than that in Model 1, and the supplier will earn more revenue than that in Model 2 based on the CE in the supplier's utility function. Second, the coefficient of variation will be used to make the selection when there are more than one feasible alternatives. Including the quality risk and CE in the operation changing process will not only benefit the retailer but also provide the supplier a conservative and more accurate estimate of his total revenue and thus determine a reliable charge rate for both members. A numerical example is provided to illustrate the two models and the proposed coordination scheme, along with the effects of several important parameters on this example.

\section{Acknowledgments}

The authors are grateful to the referees for their constructive comments and helpful suggestions that led to significant improvement in the content and presentation of the paper.

\section{References}

[1] I. Giannoccaro and P. Pontrandolfo, "Supply chain coordination by revenue sharing contracts," International Journal of Production Economics, vol. 89, no. 2, pp. 131-139, 2004.

[2] F. Bernstein and A. Federgruen, "Pricing and replenishment strategies in a distribution system with competing retailers," Operations Research, vol. 51, no. 3, pp. 409-426, 2003.

[3] G. P. Cachon, "The allocation of inventory risk in a supply chain: push, pull, and advance-purchase discount contracts," Management Science, vol. 50, no. 2, pp. 222-238, 2004.

[4] Y. Wang, L. Jiang, and Z.-J. Shen, "Channel performance under consignment contract with revenue sharing," Management Science, vol. 50, no. 1, pp. 34-47, 2004.

[5] M. K. Mantrala and S. Rao, "A decision-support system that helps retailers decide order quantities and markdowns for fashion good," Interfaces, vol. 31, no. 3, pp. 146-165, 2001.

[6] S. J. Whang, "Markdown competition," in Retail Supply Chain Management, N. Aggrawal and S. A. Smith, Eds., pp. 1-15, Springer, Berlin, Germany, 2009.

[7] R. Yin, Y. Aviv, A. Pazgal, and C. S. Tang, "Optimal markdown pricing: implications of inventory display formats in the presence of strategic customers," Management Science, vol. 55, no. 8, pp. 1391-1408, 2009.

[8] B. Shen, T. M. Choi, Y. Wang, and K. Y. Lo, "The coordination of fashion supply chains with a risk-averse supplier under the markdown money policy," IEEE Transactions on Systems, Man and Cybernetics: Systems, vol. 43, no. 2, pp. 266-276, 2013.

[9] H. Emmons and S. M. Gilbert, "Note. The role of returns policies in pricing and inventory decisions for catalogue goods," Management Science, vol. 44, no. 2, pp. 276-283, 1998.

[10] A. H.-L. Lau, H.-S. Lau, and K. D. Willett, "Demand uncertainty and returns policies for a seasonal product: an alternative model," International Journal of Production Economics, vol. 66, no. 1, pp. 1-12, 2000.

[11] T.-M. Choi, D. Li, and H. Yan, "Mean-variance analysis of a single supplier and retailer supply chain under a returns policy," European Journal of Operational Research, vol. 184, no. 1, pp. 356-376, 2008.

[12] T. A. Taylor, "Supply chain coordination under channel rebates with sales effort effects," Management Science, vol. 48, no. 8, pp. 992-1007, 2002.

[13] C.-H. Chiu, T.-M. Choi, H.-T. Yan, and Y. Zhao, "Sales rebate contracts in fashion supply chains," Mathematical Problems in Engineering, vol. 2012, Article ID 908408, 19 pages, 2012.

[14] J. V. Jucker and M. J. Rosenblatt, "Single-period inventory models with demand uncertainty and quantity discounts: behavioral implications and a new solution procedure," Naval Research Logistics Quarterly, vol. 32, no. 4, pp. 537-550, 1985.

[15] C.-S. Lin and D. E. Kroll, "The single-item newsboy problem with dual performance measures and quantity discounts," European Journal of Operational Research, vol. 100, no. 3, pp. 562-565, 1997. 
[16] G. P. Cachon and M. A. Lariviere, "Supply chain coordination with revenue-sharing contracts: strengths and limitations," Management Science, vol. 51, no. 1, pp. 30-44, 2005.

[17] M. Xu, Q. Wang, and L. Ouyang, "Coordinating contracts for two-stage fashion supply chain with risk-averse retailer and price-dependent demand," Mathematical Problems in Engineering, vol. 2013, Article ID 259164, 12 pages, 2013.

[18] C. J. Corbett, D. Zhou, and C. S. Tang, "Designing supply contracts: vontract type and information asymmetry," Management Science, vol. 50, no. 4, pp. 550-559, 2004.

[19] J. Ru and Y. Wang, "Consignment contracting: who should control inventory in the supply chain?" European Journal of Operational Research, vol. 201, no. 3, pp. 760-769, 2010.

[20] A. A. Tsay, "The quantity flexibility contract and supplier-customer incentives," Management Science, vol. 45, no. 10, pp. 13391358, 1999.

[21] F. Y. Chen, H. Yan, and L. Yao, "A newsvendor pricing game," IEEE Transactions on Systems, Man, and Cybernetics Part A, vol. 34, no. 4, pp. 450-456, 2004.

[22] F. J. Arcelus, S. Kumar, and G. Srinivasan, "Pricing, rebate, advertising and ordering policies of a retailer facing pricedependent stochastic demand in newsvendor framework under different risk preferences," International Transactions in Operational Research, vol. 13, no. 3, pp. 209-227, 2006.

[23] J.-Y. Gotoh and Y. Takano, "Newsvendor solutions via conditional value-at-risk minimization," European Journal of Operational Research, vol. 179, no. 1, pp. 80-96, 2007.

[24] Y. Qin, R. Wang, A. J. Vakharia, Y. Chen, and M. M. H. Seref, "The newsvendor problem: review and directions for future research," European Journal of Operational Research, vol. 213, no. 2, pp. 361-374, 2011.

[25] E. A. Silver, D. F. Pyke, and R. Peterson, Inventory Management and Production Planning and Scheduling, John Wiley \& Sons, New York, NY, USA, 1998.

[26] G. Gallego and I. Moon, "Distribution free newsboy problem: review and extensions," Journal of the Operational Research Society, vol. 44, no. 8, pp. 825-834, 1993.

[27] K. Pan, K. K. Lai, S. C. H. Leung, and D. Xiao, "Revenue-sharing versus wholesale price mechanisms under different channel power structures," European Journal of Operational Research, vol. 203, no. 2, pp. 532-538, 2010.

[28] C.-H. Wang, "The impact of a free-repair warranty policy on EMQ model for imperfect production systems," Computers and Operations Research, vol. 31, no. 12, pp. 2021-2035, 2004.

[29] J. A. A. van der Veen and V. Venugopal, "Using revenue sharing to create win-win in the video rental supply chain," Journal of the Operational Research Society, vol. 56, no. 7, pp. 757-762, 2005.

[30] C. Koulamas, "A newsvendor problem with revenue sharing and channel coordination," Decision Sciences, vol. 37, no. 1, pp. 91100, 2006.

[31] S. Li, Z. Zhu, and L. Huang, "Supply chain coordination and decision making under consignment contract with revenue sharing," International Journal of Production Economics, vol. 120, no. 1, pp. 88-99, 2009.

[32] C. T. Linh and Y. Hong, "Channel coordination through a revenue sharing contract in a two-period newsboy problem," European Journal of Operational Research, vol. 198, no. 3, pp. 822-829, 2009.

[33] R. T. Clemen and T. Reilly, Making Hard Decisions, Duxbury, Singapore, 2001.
[34] M. Khouja, "The single-period (news-vendor) problem: literature review and suggestions for future research," Omega, vol. 27, no. 5, pp. 537-553, 1999.

[35] P. McNamee and J. Celona, Decision Analysis for the Professional with Super Tree, Scientific Press, Redwod City, Calif, USA, 1987. 


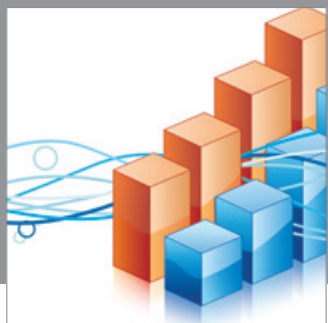

Advances in

Operations Research

mansans

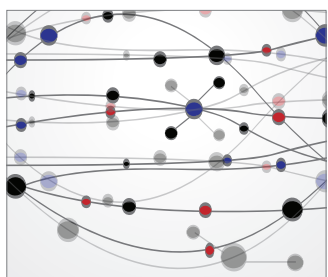

The Scientific World Journal
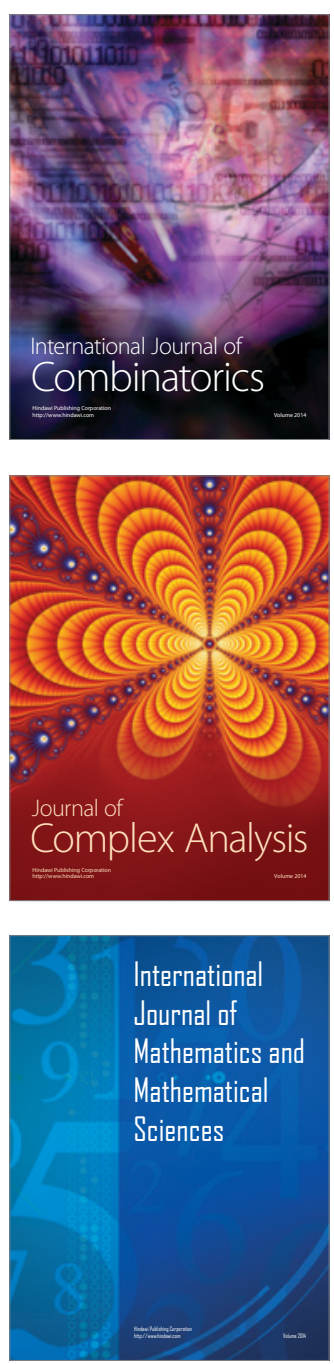
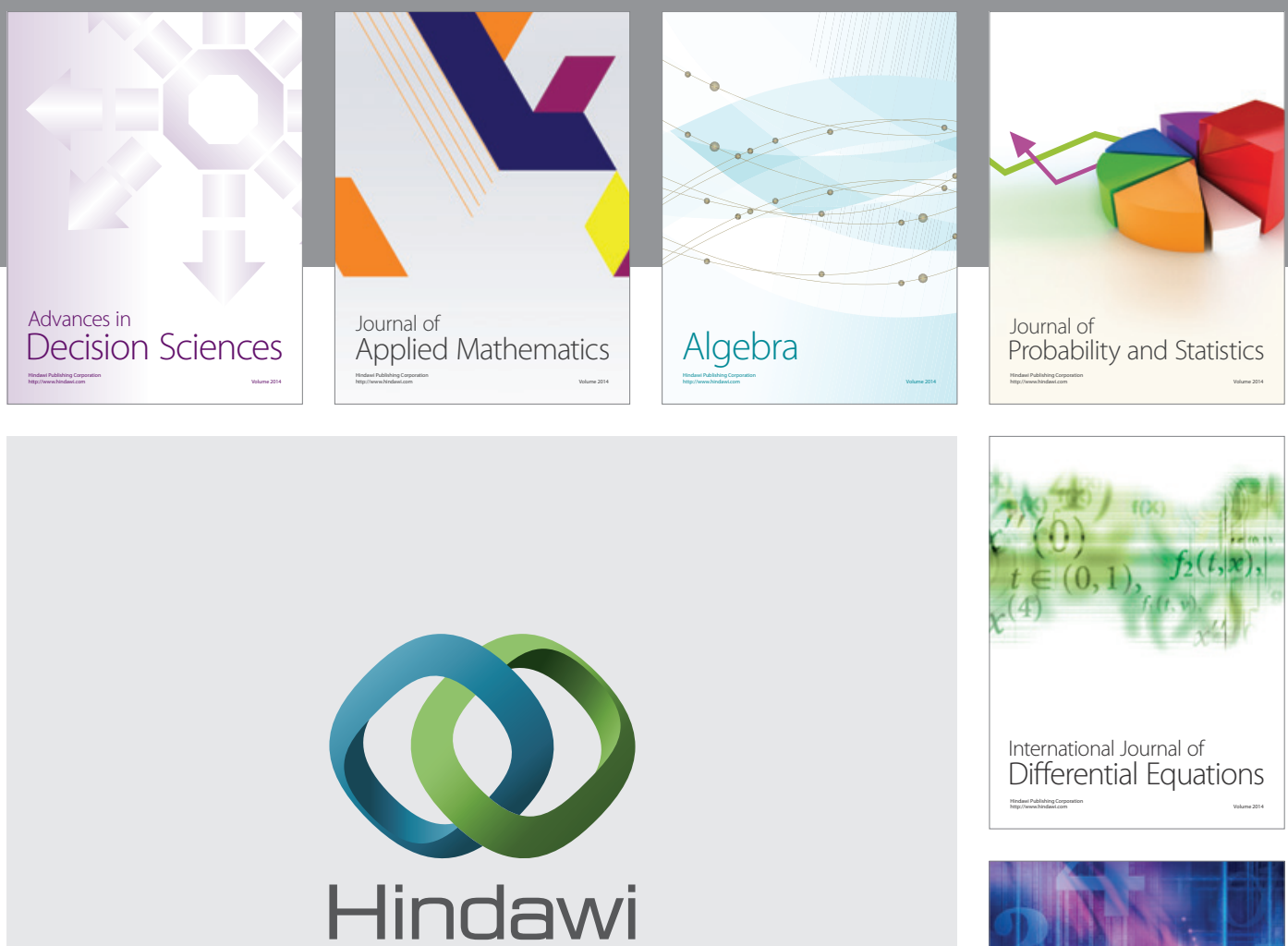

Submit your manuscripts at http://www.hindawi.com
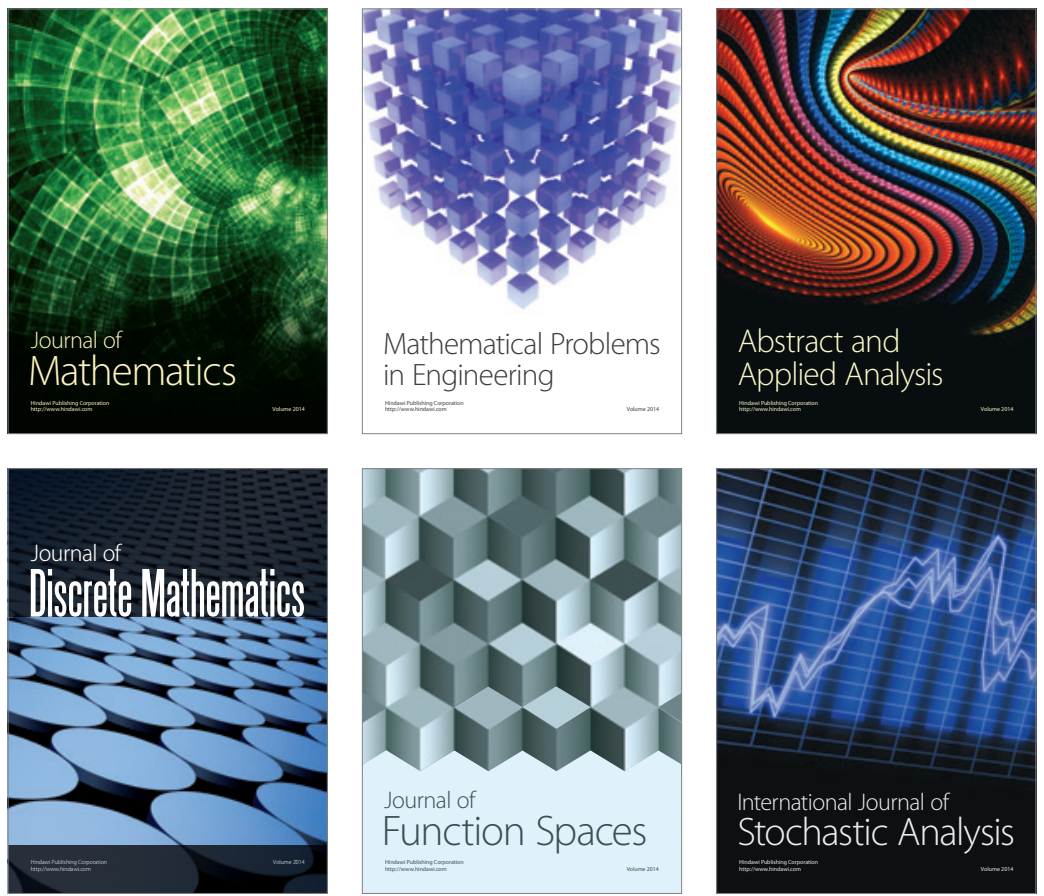

Journal of

Function Spaces

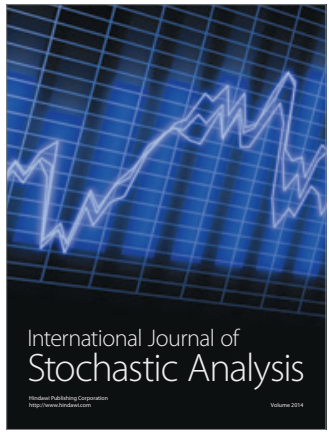

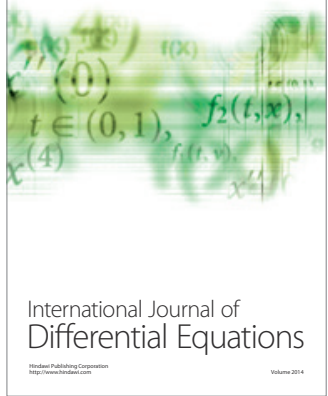
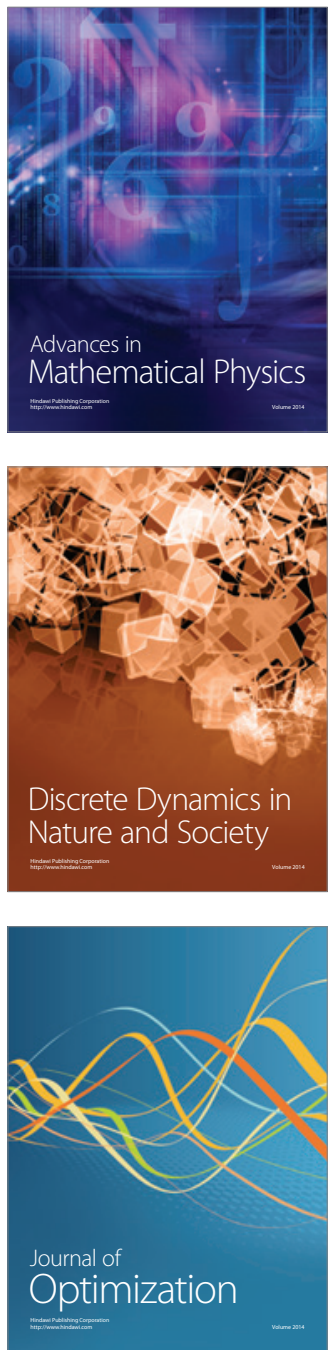